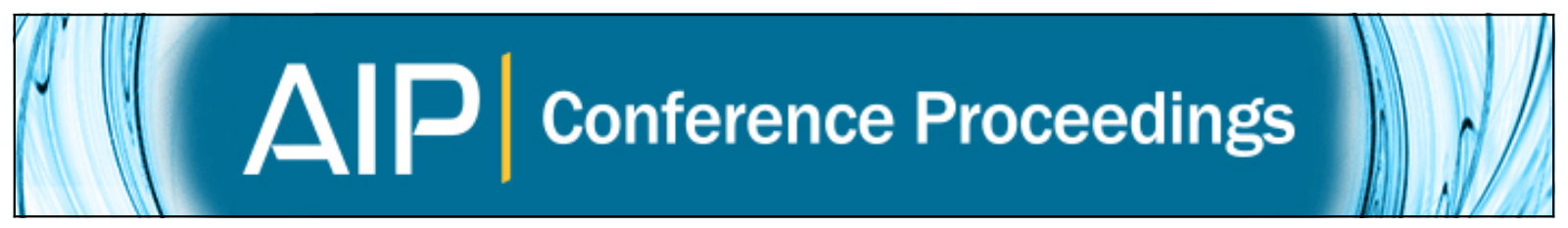

\title{
Atmospheric nucleation and growth in the CLOUD experiment at CERN
}

Jasper Kirkby and CLOUD Collaboration

Citation: AIP Conference Proceedings 1527, 278 (2013); doi: 10.1063/1.4803258

View online: http://dx.doi.org/10.1063/1.4803258

View Table of Contents: http://scitation.aip.org/content/aip/proceeding/aipcp/1527?ver=pdfcov

Published by the AIP Publishing

Articles you may be interested in

Multi-species nucleation rates in CLOUD

AIP Conf. Proc. 1527, 326 (2013); 10.1063/1.4803269

Ternary $\mathrm{H} 2 \mathrm{SO} 4$ - $\mathrm{H} 2 \mathrm{O}-\mathrm{NH} 3$ neutral and charged nucleation rates for a wide range of atmospheric conditions

AIP Conf. Proc. 1527, 310 (2013); 10.1063/1.4803265

Observations and models of particle nucleation near cloud outflows

AIP Conf. Proc. 534, 831 (2000); 10.1063/1.1361988

Application of nucleation theories to atmospheric aerosol formation

AIP Conf. Proc. 534, 711 (2000); 10.1063/1.1361961

Laboratory studies of ice nucleation in sulfate particles: Implications for cirrus clouds

AIP Conf. Proc. 534, 471 (2000); 10.1063/1.1361909 


\title{
Atmospheric Nucleation and Growth in the CLOUD Experiment at CERN
}

\author{
Jasper Kirkby and the CLOUD collaboration ${ }^{\mathrm{b}}$ \\ ${ }^{a}$ CERN, CH-1211 Geneva, Switzerland \\ ${ }^{b}$ Aerodyne Research Inc., Billerica, Massachusetts 01821, USA \\ California Institute of Technology, Division of Chemistry and Chemical Engineering, Pasadena, \\ California 91125, USA \\ Carnegie Mellon University, Dep. of Chemical Engineering, Pittsburgh PA 15213-3890, USA \\ Finnish Meteorological Institute, FI-00101 Helsinki, Finland \\ Goethe-University of Frankfurt, Institute for Atmospheric and Environmental Sciences, 60438 \\ Frankfurt am Main, Germany \\ Helsinki Institute of Physics, University of Helsinki, FI-00014 Helsinki, Finland \\ Karlsruhe Institute of Technology, Institute for Meteorology and Climate Research - Atmospheric \\ Aerosol Research, 76344 Eggenstein-Leopoldshafen, Germany \\ Lebedev Physical Institute, Solar and Cosmic Ray Research Laboratory, 119991 Moscow, Russia \\ Leibniz Institute for Tropospheric Research, 04318 Leipzig, Germany \\ Paul Scherrer Institute, Laboratory of Atmospheric Chemistry, CH-5232 Villigen, Switzerland \\ TOFWERK AG, CH-3600 Thun, Switzerland \\ University of Eastern Finland, FI-70211 Kuopio, Finland \\ University of Helsinki, Department of Physics, FI-00014 Helsinki, Finland \\ University of Innsbruck, Institute for Ion and Applied Physics, 6020 Innsbruck, Austria \\ University of Leeds, School of Earth and Environment, LS2-9JT Leeds, United Kingdom \\ University of Lisbon and University of Beira Interior, 1749-016 Lisbon, Portugal \\ University of Manchester, School of Earth, Atmospheric and Environmental Sciences, Manchester \\ M13 9PL, United Kingdom \\ University of Stockholm, Department of Applied Environmental Science, 10691 Stockholm, Sweden \\ University of Vienna, Faculty of Physics, 1090 Vienna, Austria
}

\begin{abstract}
Nucleation and growth of new particles in the atmosphere is thought to account for up to half of all cloud condensation nuclei. However the vapours and formation rates that underly this process are poorly understood, due both to the ultra low concentrations of participating vapours in the presence of high backgrounds and to the many sources of uncontrolled variability in the atmosphere. In consequence, laboratory measurements made under clean and precisely controlled conditions play an important role in identifying the vapours responsible and quantifying their associated nucleation and growth rates. The CLOUD experiment at CERN is studying the nucleation and growth of aerosol particles, and their interaction with clouds, in a $3 \mathrm{~m}$ stainless steel aerosol/cloud chamber. The experiment is optimised to study the influence of ions, for which the CERN Proton Synchrotron (PS) provides an adjustable source of 'cosmic rays'. Extraordinary care has been paid in the design and construction of CLOUD and its associated systems - gas, thermal, UV and electric field-to suppress contaminants at the technological limit. The unprecedented low contamination achieved in the CLOUD chamber has revealed that atmospheric nucleation and growth is sensitive to certain atmospheric vapours at mixing ratios of only a few parts-per-trillion by volume (pptv). Here we provide an overview of the design of CLOUD and its experimental programme over four years of operation at CERN.
\end{abstract}

Keywords: Atmospheric aerosol, nucleation, particle growth, clouds, sulphuric acid, ammonia, dimethylamine, alpha-pinene, ions, galactic cosmic rays, CERN CLOUD experiment

PACS: 92.60.Mt, 64.60.Q-, 82.33.Tb, 96.50.S

Nucleation and Atmospheric Aerosols

(C) 2013 AIP Publishing LLC 978-0-7354-1152-4/\$30.00 


\section{INTRODUCTION}

Aerosol-cloud interactions have a major influence on climate. Aerosol particles affect cloud droplet concentrations and, in turn, influence cloud reflectivity, precipitation, lifetime, dynamics and electrification. Changes of aerosol particles in the $20^{\text {th }}$ century due to anthropogenic activities are thought to have offset a large fraction of the warming due to increased greenhouse gases [1]. However, aerosol-cloud processes are poorly understood and constitute the largest present uncertainty in radiative forcing of climate, severely limiting our ability to make accurate projections of future climate [2].

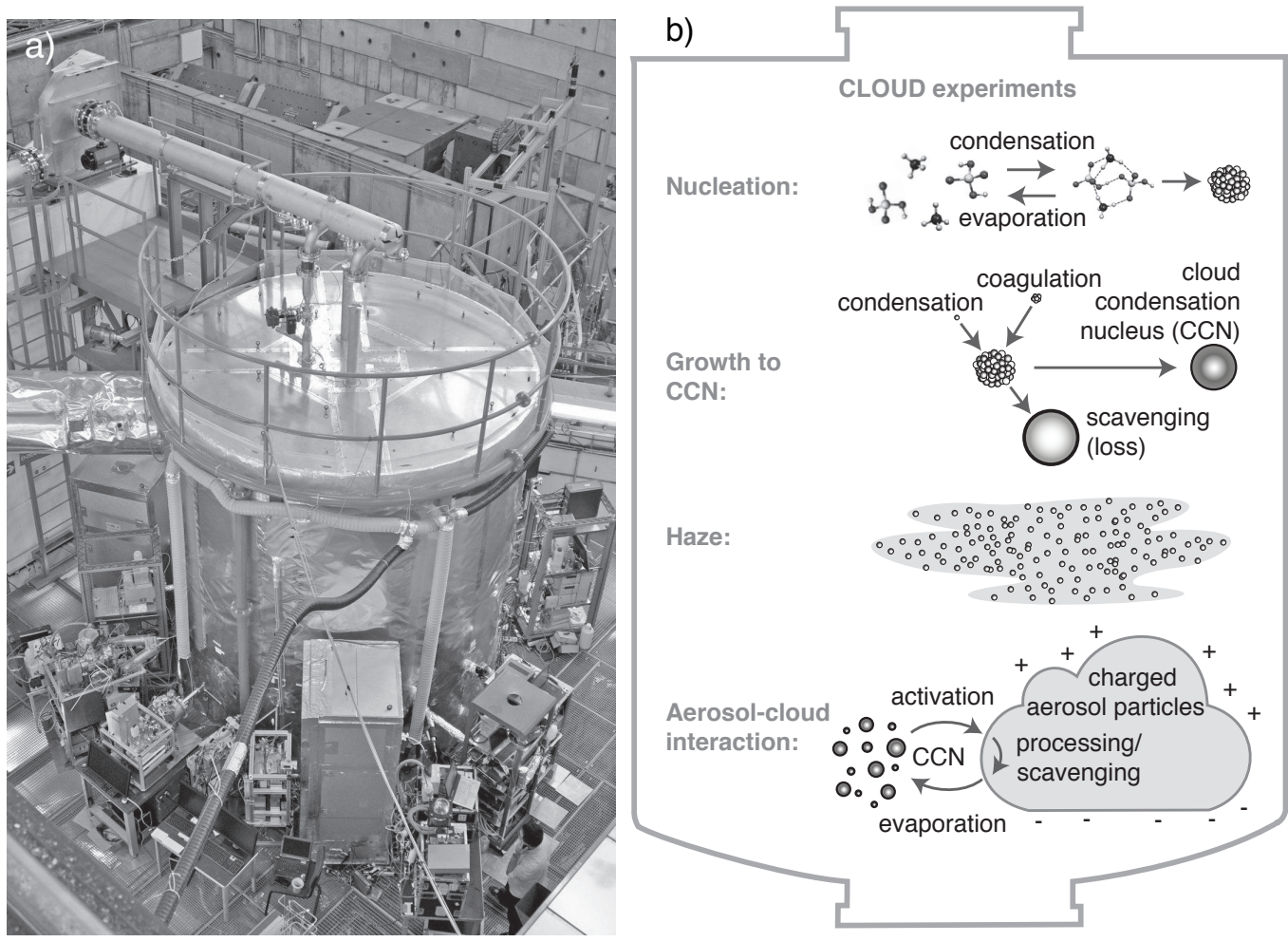

FIGURE 1. a) Experimental configuration during the CLOUD7 campaign at CERN, October-December 2012. A total of 25 sampling instruments surround the chamber at mid-height, including 9 state-of-art mass spectrometers to provide molecular analysis of vapours and nucleating clusters. b) Present and future CLOUD experiments on aerosol-cloud processes in the laboratory from the nanometer molecular scale to the meter cloud scale.

Up to half of all cloud droplets are estimated to form on cloud condensation nuclei $(\mathrm{CCN})$ that were nucleated from trace vapours rather than being directly emitted into the atmosphere as particles [3]. The CLOUD experiment at CERN (Fig. 1a) aims to resolve the fundamental physical and chemical processes involved in the formation of cloud-active aerosols, their growth to $\mathrm{CCN}$ sizes and their interaction with haze and clouds (Fig. 1b). The experiment will measure, in particular, the influence of ions on these processes. Since ions in the free troposphere and the marine boundary layer result mainly from galactic cosmic rays (GCRs), their role in atmospheric nucleation is of considerable interest as a possible physical mechanism for solar-climate variability [4]. 


\section{CLOUD EXPERIMENT AT CERN}

The CLOUD chamber (Fig. 2) is a 3 m-diameter electropolished stainless steel cylinder $\left(26.1 \mathrm{~m}^{3}\right)$. The large size allows nucleation and growth processes to be studied at atmospheric concentrations, which are characterised by slow collision rates and cluster growth rates. Manhole covers of $1 \mathrm{~m}$ diameter are located at the top and bottom of the chamber to allow internal access. The chamber is equipped with numerous ports to allow installation of electrical/optical feedthroughs and sampling probes to extract air samples. Two transparent electrodes operating at voltages up to $30 \mathrm{kV}$ are installed inside the chamber to simulate an ion-free environment. The contents of the chamber can be irradiated by ultra violet (UV) light in the range $250-400 \mathrm{~nm}$. The UV is introduced via 240 optical fibre vacuum feedthroughs installed on the top plate of the chamber. These provide a uniform UV irradiation inside the chamber for photolytic reactions, without any parasitic heat load. All materials and procedures used for the chamber are chosen to suppress contaminant vapours at the technological limit.

The chamber normally operates at +5 mbar relative to atmospheric pressure. However the chamber and gas system are designed to operate at up to +200 mbar relative pressure and to make controlled adiabatic expansions down to +5 mbar. In this way, starting from relative humidities near $100 \%$, the chamber can be operated as a classical Wilson cloud

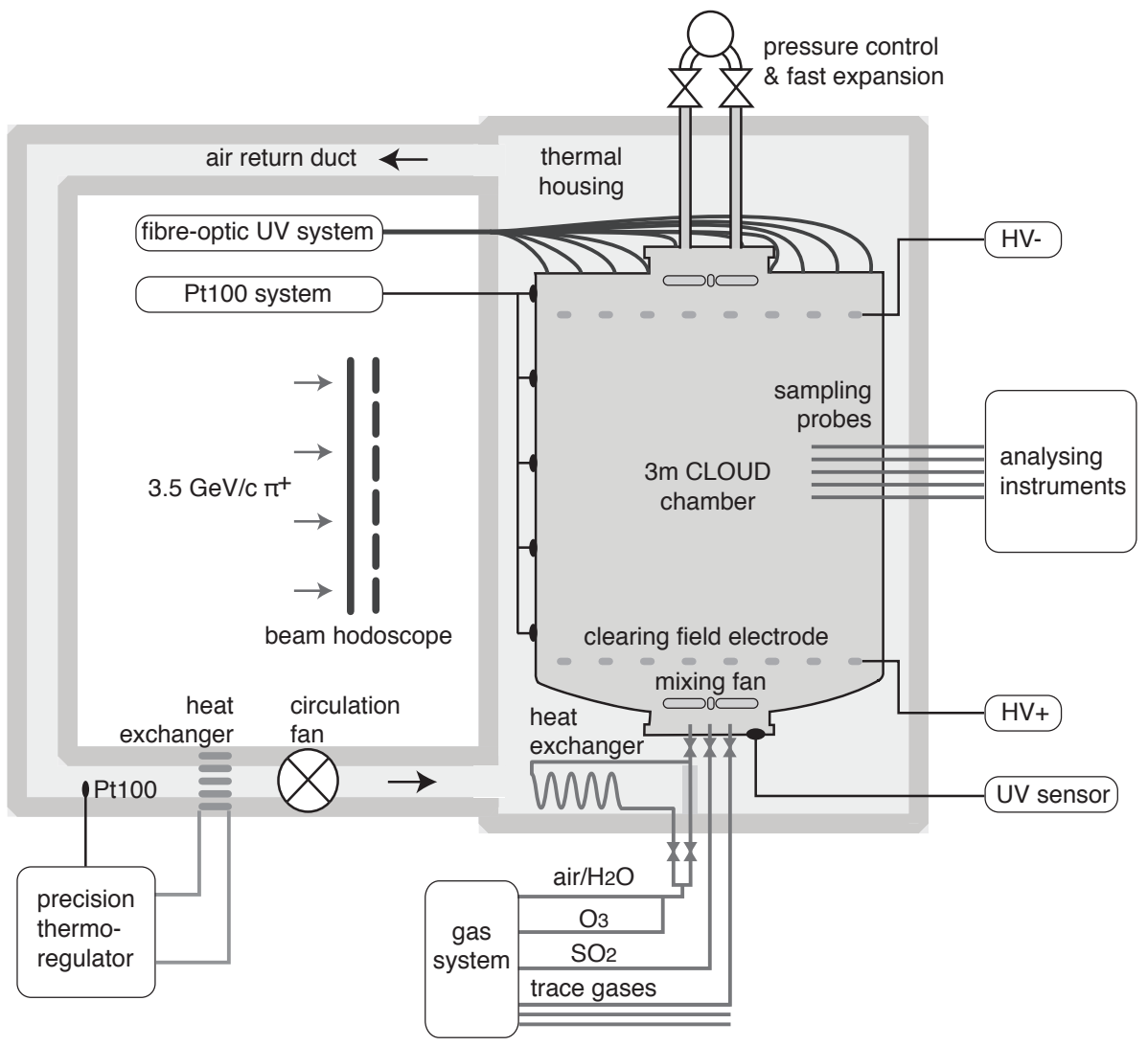

FIGURE 2. Schematic of the CLOUD experiment at CERN. 
chamber for studies of ion-aerosol interactions with cloud droplets and ice particles.

The chamber is surrounded by an insulated thermal housing. The temperature is controlled by precisely regulating the temperature of the air circulating in the space between the chamber and the thermal housing. Experimental runs can be performed at highly-stable temperatures (near $0.01^{\circ} \mathrm{C}$ ) between $40^{\circ} \mathrm{C}$ and $-70^{\circ} \mathrm{C}$. In addition, the chamber can be raised to $100^{\circ} \mathrm{C}$ for bakeout.

The chamber is exposed to a $3.5 \mathrm{GeV} / \mathrm{c}$ secondary $\pi^{+}$beam from the CERN PS, corresponding to the characteristic energies and ionisation densities of cosmic ray muons in the lower troposphere. The beam intensity can be adjusted to generate an ion-pair concentration in the chamber spanning the atmospheric range from ground level to the stratosphere.

Ultra-pure synthetic air is obtained from the evaporation of cryogenic liquid $\mathrm{N}_{2}$ and liquid $\mathrm{O}_{2}$, mixed in the ratio 79:21, respectively. The air is humidified using ultra-pure water from a filtered re-circulation system. A new ultra-pure water source is being developed to deliver synthetic water from burning electrolytically-produced $\mathrm{H}_{2}$ in pure $\mathrm{O}_{2}$ at $1400{ }^{\circ} \mathrm{C}$. Ozone is added to the chamber by UV irradiation of a small inlet flow of

dry air. Each trace gas delivered to the chamber has a dedicated line and isolation valve located at the chamber entrance, under the lower manhole cover. Magnetically-coupled stainless steel fans on both manhole covers serve to mix the fresh gases and beam ions, and ensure uniformity inside the chamber. Volatile trace gases such as $\mathrm{SO}_{2}$ or $^{\mathrm{NH}_{3}}$ are supplied from concentrated gas cylinders pressurised with $\mathrm{N}_{2}$ carrier gas. The trace gas mixtures are highly diluted using synthetic air before injection into the chamber. Less volatile trace gases such as alpha-pinene $\left(\mathrm{C}_{10} \mathrm{H}_{16}\right)$ or pinanediol $\left(\mathrm{C}_{10} \mathrm{H}_{18} \mathrm{O}_{2}\right)$ are supplied from temperature-controlled stainless steel evaporators using ultrapure $\mathrm{N}_{2}$ carrier gas. Chemically-produced trace vapours such as nitrous acid (HONO) are supplied from custom-built stainless steel reactors. In order to compensate for sampling losses, there is a continuous flow of fresh gases into the chamber of up to $140 \mathrm{l} / \mathrm{min}$, resulting in a dilution lifetime of about $3 \mathrm{~h}$.

A comprehensive array of state-of-the-art instruments continuously samples and analyses the contents of the chamber. The instrumentation during the recent CLOUD7 campaign is summarised in Table 1.

\section{EXPERIMENTAL PROGRAMME}

CLOUD has been in operation at CERN since November 2009. So far there have been two measurement campaigns per year, each of around 2 months, during which CLOUD collects data continuously, 24 hours per day. Each afternoon during a campaign the findings from the previous day's data are discussed in the CLOUD control room and the chamber conditions decided for the next 24 hours of data. These " 3 o'clock meetings" are experimental science at its best.

The main focus during the seven CLOUD campaigns so far has been aerosol particle nucleation and growth, and, in particular, the effect of ions on these processes (Table 2). Binary and ammonia ternary nucleation were studied during the first three campaigns (CLOUD1-3). These measurements were extended to free tropospheric conditions (temperatures down to $208 \mathrm{~K}$ ) in CLOUD5. Nucleation and growth in the presence of ox- 
TABLE 1. CLOUD instrumentation during the CLOUD7 campaign, October-December 2012.

\begin{tabular}{|c|c|c|c|c|}
\hline Mass spectrometers & Particle counters & Particle sizers & Particle analysers & Gas analysers \\
\hline $\begin{array}{l}\text { APITOF- } \\
\text { APITOF+ } \\
\text { CI-APITOF_1 } \\
\text { CI-APITOF_2 } \\
\text { CIMS } \\
\text { IMS-TOF } \\
\text { NAIS } \\
\text { PTRTOF } \\
\text { TDCIMS }\end{array}$ & $\begin{array}{l}\text { PSM_1.1 } \\
\text { DEG-CPC_1.7 } \\
\text { DEG-CPC_2.0 } \\
\text { CPC_3.2 } \\
\text { CPC 3010 }\end{array}$ & $\begin{array}{l}\text { scanning PSM } \\
\text { radial DMA } \\
\text { LDT } \\
\text { SMPS }\end{array}$ & $\begin{array}{l}\text { HTDMA } \\
\text { OTDMA }\end{array}$ & $\begin{array}{l}\mathrm{IC} \\
\mathrm{LOPAP} \\
\mathrm{SO}_{2} \\
\mathrm{O}_{3} \\
\text { dewpoint }\end{array}$ \\
\hline
\end{tabular}

\section{Key:}

APITOF

CI-APITOF

CIMS

CPC

DEG-CPC

DMA

HTDMA

IC

IMS-TOF

LDT

LOPAP

NAIS

OTDMA

PSM

PTRTOF

SMPS

TDCIMS atmospheric pressure interface time of flight mass spectrometer

chemical ionisation APITOF

chemical ionisation mass spectrometer

condensation particle counter

diethylene glycol CPC

differential mobility analyser

hygroscopic tandem DMA

ion chromatograph

ion mobility spectrometer - time of flight mass spectrometer

laminar diffusion tube $\mathrm{CPC}$

long path absorption photometer

neutral cluster and air ion spectrometer

organic tandem DMA

particle size magnifier

proton transfer reaction time of flight mass spectrometer

scanning mobility particle sizer

thermal desorption chemical ionisation mass spectrometer

TABLE 2. CLOUD experimental campaigns at CERN.

\begin{tabular}{llll}
\hline Campaign & Month & Year & Aim \\
\hline CLOUD1 & Nov-Dec & 2009 & Commissioning \\
CLOUD2 & Jun-Jul & 2010 & Binary $\mathrm{H}_{2} \mathrm{SO}_{4}, \mathrm{NH}_{3}$ ternary nucleation \\
CLOUD3 & Oct-Nov & 2010 & Binary $\mathrm{H}_{2} \mathrm{SO}_{4}, \mathrm{NH}_{3}$ ternary nucleation \\
CLOUD4 & Jun-Jul & 2011 & Dimethylamine \& pinanediol ternary nucleation \\
CLOUD5 & Oct-Nov & 2011 & Free tropospheric binary $\mathrm{H}_{2} \mathrm{SO}_{4}, \mathrm{NH}_{3}$ ternary nucleation \\
CLOUD6 & Jun & 2012 & Initial cloud formation experiments \\
CLOUD7 & Oct-Dec & 2012 & $\mathrm{NH}_{3}$, dimethylamine \& alpha-pinene ternary nucleation \& growth \\
\hline
\end{tabular}

idised organic species was studied in CLOUD4 (dimethylamine and pinanediol) and CLOUD7 (dimethylamine and alpha-pinene). Separate studies were carried out for oxidation of alpha-pinene by ozone or by $\mathrm{OH}$ radicals. Complex mixtures involving multicomponent vapours characteristic of the atmospheric boundary layer were also studied. Finally, CLOUD6 was devoted to an initial study of cloud formation in the CLOUD chamber at temperatures down the homogeneous freezing point of water near $235 \mathrm{~K}$. 


\section{RESULTS}

A typical measurement sequence from an early CLOUD run is shown in Fig. 3. The nucleation rates are measured under neutral $\left(J_{n}\right)$, ground-level galactic cosmic ray $\left(J_{g c r}\right)$, or charged pion beam $\left(J_{c h}\right)$ conditions. Neutral nucleation rates are measured without any beam and with the electric clearing field on. For GCR and beam conditions, the electric field is set to zero, leading to ion pair concentrations around $400 \mathrm{~cm}^{-3}$ for $J_{g c r}$, representative of the boundary layer, and around $3000 \mathrm{~cm}^{-3}$ for $J_{c h}$, representative of the top of the troposphere.

The first results from CLOUD showed that binary nucleation of $\mathrm{H}_{2} \mathrm{SO}_{4}-\mathrm{H}_{2} \mathrm{O}$ particles does not take place in the boundary layer except under extremely cold conditions [5]. The presence of around $100 \mathrm{pptv} \mathrm{NH}_{3}$ was found to enhance the nucleation rates by about a factor 100; while higher amounts of $\mathrm{NH}_{3}$ resulted only in small further increases in rate. Ions corresponding to ground-level GCR fluxes produced a strong enhancement of the nucleation rates by up to a factor $2-10$, depending on conditions. However, even

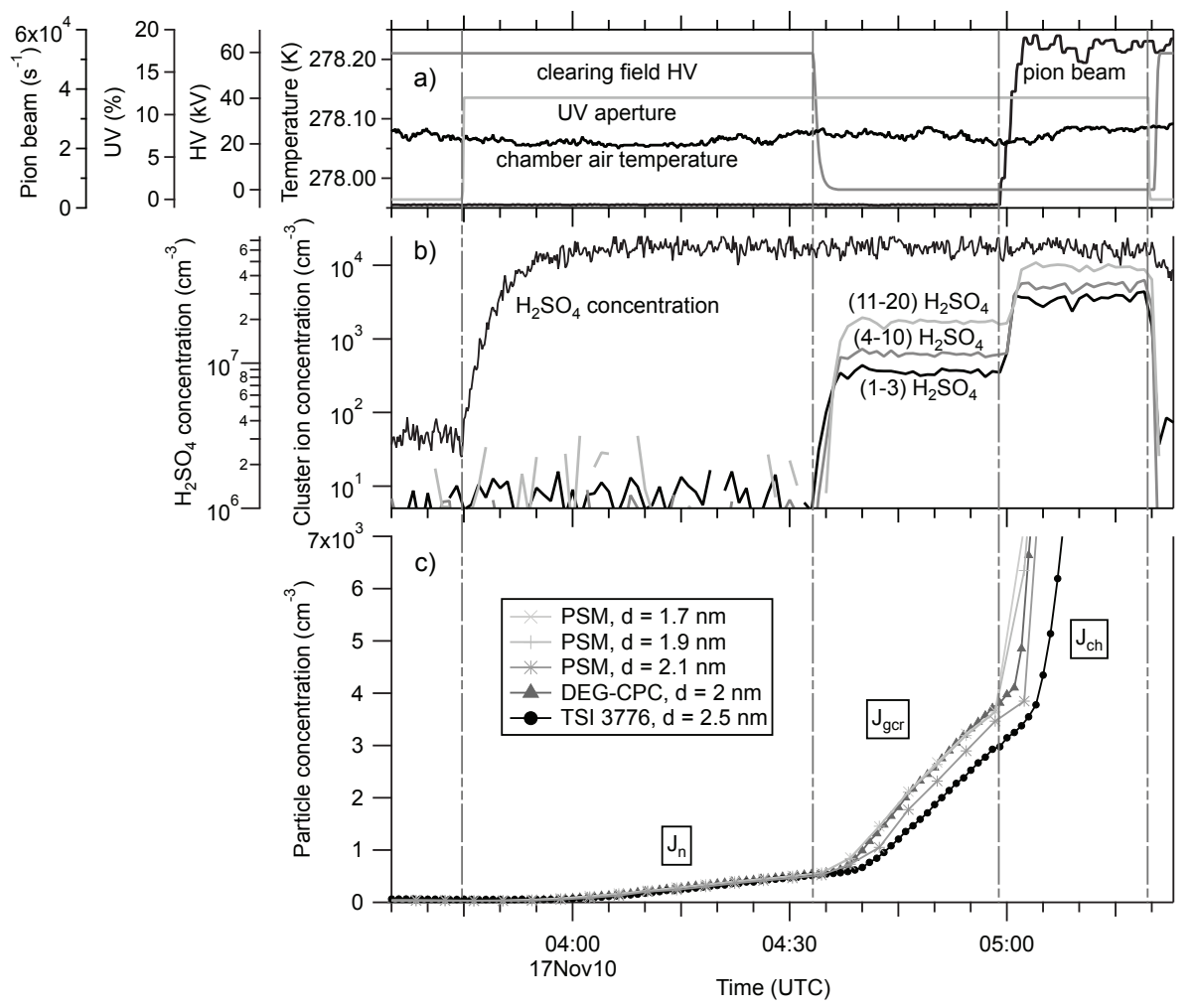

FIGURE 3. Example of a typical run sequence from the CLOUD3 campaign to measure a set of neutral, GCR and charged pion beam nucleation rates, $J_{n}, J_{g c r}$ and $J_{c h}$, respectively, at $200 \mathrm{pptv} \mathrm{NH}_{3}$ : a) control parameters and chamber air temperature, b) $\left[\mathrm{H}_{2} \mathrm{SO}_{4}\right]$ and cluster ion concentrations, and c) aerosol particle number concentrations. The production of ions from GCRs and then, at higher rate, from the pion beam causes sharp increases in the cluster ion concentrations (b) and particle formation rates (c). The onset times are progressively delayed according to the number of $\mathrm{H}_{2} \mathrm{SO}_{4}$ molecules in the cluster (b) or the $50 \%$ detection size threshold, $d$, of the particle counter (c). 
with ion enhancement, ammonia ternary nucleation still fails to explain atmospheric observations by a factor $10-100$ or more (Fig. 4).

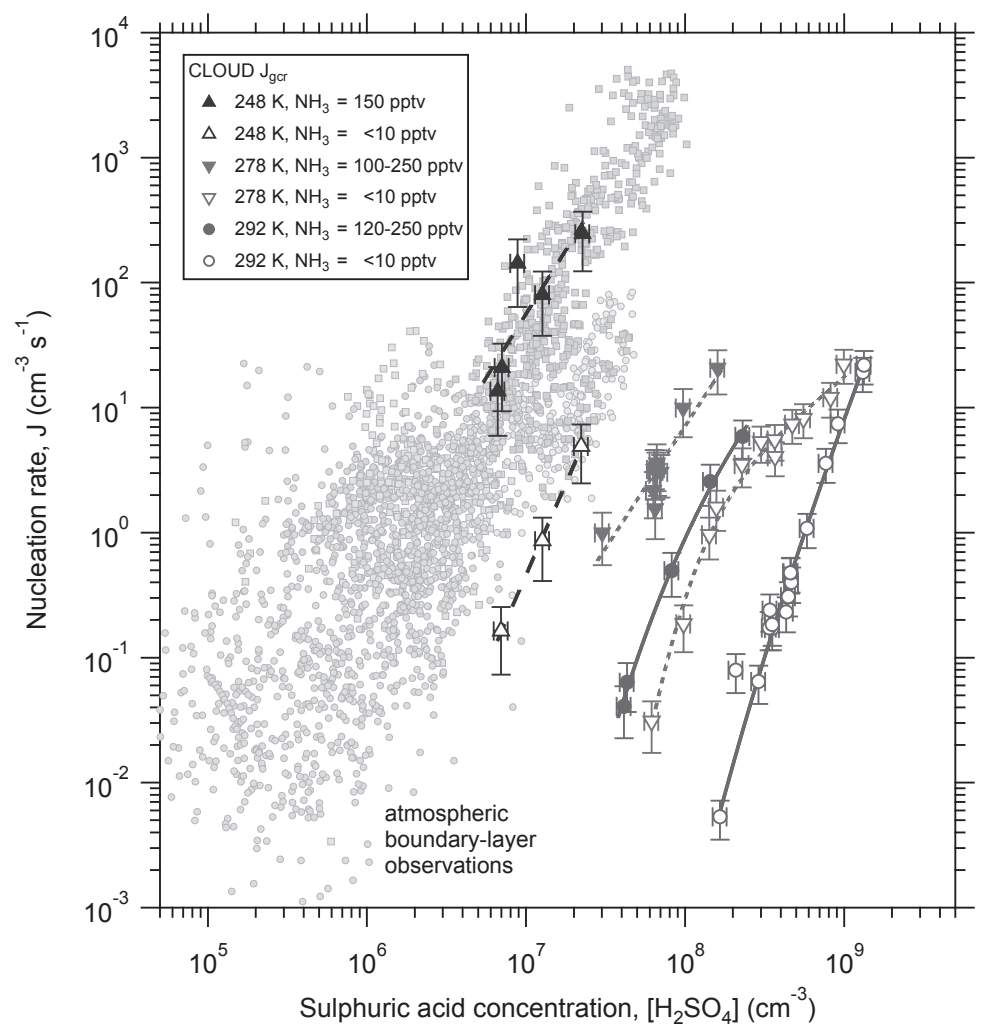

FIGURE 4. Comparison of CLOUD3 data with measurements of the nucleation rate of new particles as a function of $\left[\mathrm{H}_{2} \mathrm{SO}_{4}\right]$ in the atmospheric boundary layer [5]. The CLOUD data show the galactic cosmic ray nucleation rates, $J_{g c r}$, measured at several temperatures and $\mathrm{NH}_{3}$ mixing ratios. The measurements at $278 \mathrm{~K}$ and $292 \mathrm{~K}$ bracket the typical range of boundary layer temperatures, while $248 \mathrm{~K}$ reflects exceptionally cold conditions. Ion-induced nucleation in the boundary layer is limited by the ion-pair production rate to a maximum of about $4 \mathrm{~cm}^{-3} \mathrm{~s}^{-1}$.

The conclusion from the first CLOUD results is that organic vapours must be participating in boundary layer nucleation. This motivated the CLOUD4 and CLOUD7 campaigns, which studied dimethylamine $\left(\mathrm{C}_{2} \mathrm{H}_{7} \mathrm{~N}\right)$, alpha-pinene $\left(\mathrm{C}_{10} \mathrm{H}_{16}\right)$ and a closelyrelated species, pinanediol $\left(\mathrm{C}_{10} \mathrm{H}_{18} \mathrm{O}_{2}\right)$. One of the important results from the first CLOUD measurements was the discovery of the base-stabilisation mechanism for ammonia ternary nucleation, involving the formation of strongly bound acid-base pairs which reduce evaporation from the cluster [5]. Dimethylamine was selected in these subsequent studies since it is expected to have stronger acid-base cluster binding energies than $\mathrm{NH}_{3}$ [6]. Alpha-pinene was selected as a principal species of biogenic monoterpene, frequently found in the boundary layer at mixing ratios of a few 100 pptv or more. The initial (CLOUD4) measurements of nucleation in the presence of oxidised organics were made with pinanediol in order to control the start of nucleation using UV (unlike alpha-pinene, the ozonolysis rate of pinanediol is very slow since there is no $\mathrm{C}=\mathrm{C}$ double bond). An example of some nucleation events from CLOUD7 is shown in Fig. 5. 


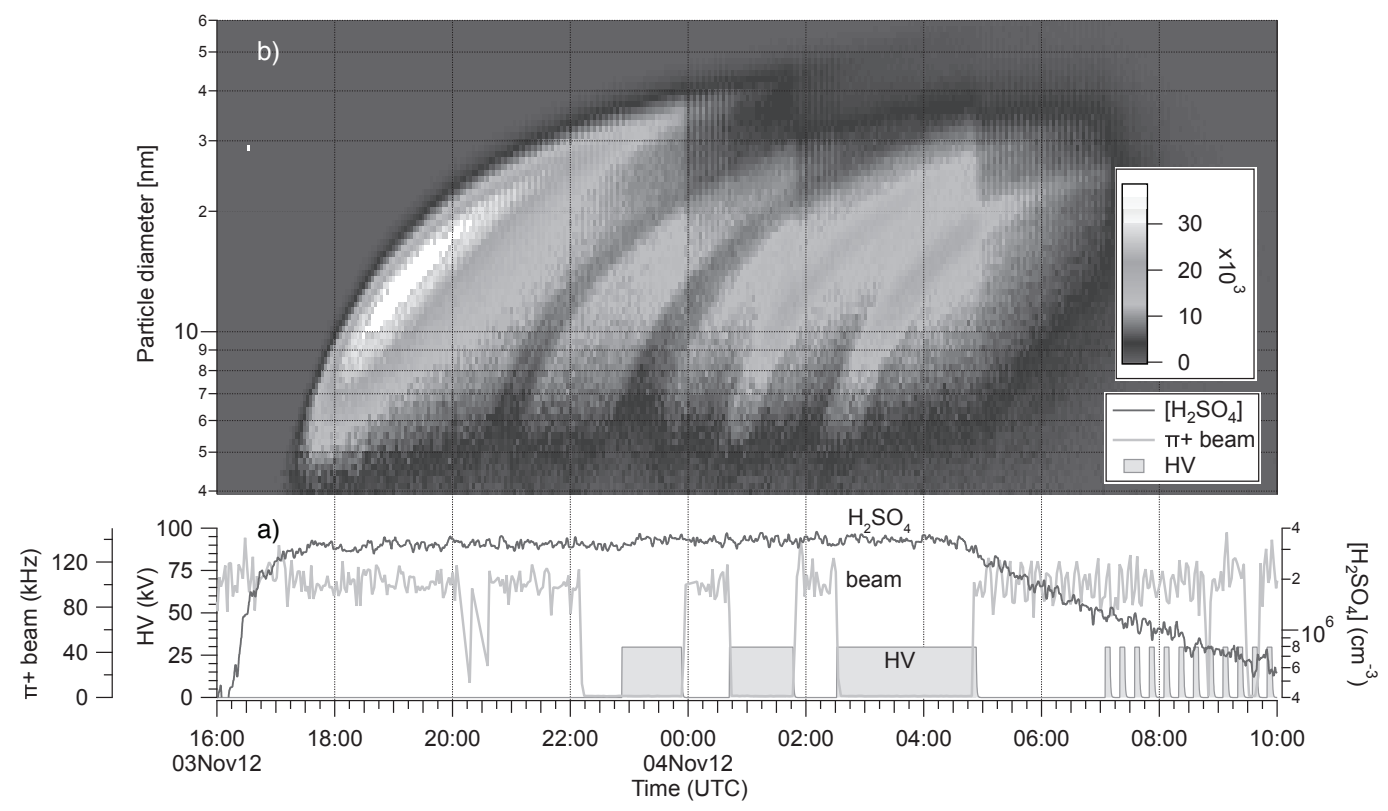

FIGURE 5. Example of ion-induced particle formation during the CLOUD7 campaign. a) The run started at 16:11, 3 November 2012, when the fibre-optic UV system was turned on to establish $4 \cdot 10^{6} \mathrm{~cm}^{-3}$ $\left[\mathrm{H}_{2} \mathrm{SO}_{4}\right]$ in the chamber. The UV is turned off at 04:49, 4 November 2012, and the chamber cleared of aerosol particles in preparation for the next run. During the run, only the ionisation conditions were varied in the CLOUD chamber, by adjustments of the beam intensity and/or high voltage clearing field, as indicated. b) The variations of ionisation produced a strong response in the rate of nucleation of new particles, as shown by nucleation bursts (banana-shaped events) recorded in the scanning mobility particle sizer (SMPS).

\section{CONCLUSIONS}

Interpretation of atmospheric observations of aerosol particle nucleation and growth is difficult in the presence of many sources of variability and 'spectator' background vapours. Laboratory experiments like CLOUD, made under clean and preciselycontrolled conditions, can identify the vapours responsible for these processes, reveal the underlying molecular mechanisms and quantify the rates. However, the parameter space is so large that laboratory experiments must be guided by atmospheric observations and theoretical work to select the most promising vapours and conditions for detailed study. Laboratory experiments and field observations are therefore complementary and essential for each other.

The ultimate goal of this work is to understand the effect of atmospheric nucleation and aerosols on global $\mathrm{CCN}$ and climate, and hence to reduce the uncertainties on aerosol radiative forcing of climate and sharpen the projections of future climate change. To do this requires a close interaction between, on the one hand, the laboratory and field measurements and, on the other hand, global models that incorporate ions, aerosol and clouds at the microphysical level. In particular, the models need to identify at the process level the key sources of uncertainty in the radiative forcing of climate by aerosols in 
order to help focus the experimental measurements on reducing these uncertainties [7].

In addition, the question of whether, and to what extent, the climate is influenced by solar and cosmic ray variability remains vital for our understanding of the anthropogenic contribution to present climate change. Real progress on the cosmic ray-climate question will require a climatically-significant physical mechanism to be established, or else ruled out. The CERN CLOUD experiment aims to provide a definitive answer to this question over the next few years by studying the effects of ions on aerosol nucleation and growth and on cloud microphysical processes.

\section{ACKNOWLEDGMENTS}

We would like to thank CERN for supporting CLOUD with important technical and financial resources, and for providing a particle beam from the CERN Proton Synchrotron. This research has received funding from the EC Seventh Framework Programme (Marie Curie Initial Training Network "CLOUD-ITN" no. 215072, MC-ITN "CLOUD-TRAIN" no. 316662, and ERC-Advanced "ATMNUCLE" grant no. 227463), the German Federal Ministry of Education and Research (project nos. 01LK0902A and 01LK1222A), the Swiss National Science Foundation (project nos. 200020_135307 and 206620_130527), the Academy of Finland (Center of Excellence project no. 1118615), the Academy of Finland (135054, 133872, 251427, 139656, 139995, 137749, 141217, 141451), the Finnish Funding Agency for Technology and Innovation, the Nessling Foundation, the Austrian Science Fund (FWF; project no. P19546 and L593), the Portuguese Foundation for Science and Technology (project no. CERN/FP/116387/2010), the Swedish Research Council, Vetenskapsrådet (grant 2011-5120), the Presidium of the Russian Academy of Sciences and Russian Foundation for Basic Research (grants 0802-91006-CERN and 12-02-91522-CERN), and the U.S. National Science Foundation (grants AGS1136479 and CHE1012293).

\section{REFERENCES}

1. IPCC, Climate Change 2007: the Physical Science Basis. Contribution of Working Group I to the Fourth Assessment Report of the Intergovernmental Panel on Climate Change. Cambridge University Press (2007).

2. M.O. Andreae, C.D. Jones and P.M. Cox. Strong present-day aerosol cooling implies a hot future. Nature 435, 1187-1190 (2005).

3. J. Merikanto, D.V.Spracklen, G.W. Mann, S.J. Pickering and K.S. Carslaw. Impact of nucleation on global CCN. Atmos. Chem. Phys. 9, 8601-8616 (2009).

4. J. Kirkby. Cosmic rays and climate. Surv. Geophys. 28, 333-375 (2007).

5. J. Kirkby et al. Role of sulphuric acid, ammonia and galactic cosmic rays in atmospheric aerosol nucleation. Nature 476, 429-433 (2011).

6. T. Kurtén, V.Loukonen, H. Vehkamäki and M. Kulmala. Amines are likely to enhance neutral and ion-induced sulfuric acid-water nucleation in the atmosphere more effectively than ammonia. Atmos. Chem. Phys. 8, 4095-4103 (2008).

7. L.A. Lee, K.S. Carslaw, K.J. Pringle, G.W. Mann and D.V. Spracklen. Emulation of a complex global aerosol model to quantify sensitivity to uncertain parameters. Atmos. Chem. Phys. 11, 12253-12273 (2011). 